\title{
Spatial Distribution of the Population at Risk of Cholangiocarcinoma in Chum Phaung District, Nakhon Ratchasima Province of Thailand
}

\author{
Soraya J Kaewpitoon ${ }^{1,2,3 *}$, Ratana Rujirakul' ${ }^{1}$, Ryan A Loyd ${ }^{2}$, Likit Matrakool ${ }^{3}$, \\ Amnat Sangkudloa ${ }^{4}$,Sarochinee Kaewthani ${ }^{5}$, Kritsakorn Khemplila ${ }^{6}$, Thawatchai \\ Eaksanti $^{7}$, Tanida Phatisena ${ }^{7}$, Jirawoot Kujapun ${ }^{8}$, Jun Norkaew ${ }^{8}$, Apinya Joosiri ${ }^{1}$, \\ Natthawut Kaewpitoon ${ }^{1,3,8}$
}

\begin{abstract}
Background: Cholangiocarcinoma (CCA) is a serious health problem in Thailand, particularly in northeastern and northern regions, but epidemiological studies are scarce and the spatial distribution of CCA remains to be determined. A database for the population at risk is required for monitoring, surveillance and organization of home health care. This study aim was to geo-visually display the distribution of CCA in northeast Thailand, using a geographic information system and Google Earth. Materials and Methods: A cross-sectional survey was carried out in 9 sub-districts and 133 villages in Chum Phuang district, Nakhon Ratchasima province during June and October 2015. Data on demography, and the population at risk for CCA were combined with the points of villages, sub-district boundaries, district boundaries, and points of hospitals in districts, then fed into a geographical information system. After the conversion, all of the data were imported into Google Earth for geo-visualization. Results: A total of 11,960 from 83,096 population were included in this study. Females and male were $52.5 \%$, and $47.8 \%$, the age group $41-50$ years old 33.3\%. Individual risk for CCA was identifed and classified by using the Korat CCA verbal screening test as low $(92.8 \%)$, followed by high risk $(6.74 \%)$, and no $(0.49 \%)$, respectively. Gender $\left(X^{2}\right.$-test $=1143.63$, $p$-value $\left.=0.001\right)$, age group $\left(X^{2}\right.$-test $==211.36$, $p$-value $\left.=0.0001\right)$, and sub-district $\left(X^{2}\right.$-test $=\mathbf{1 4 7 1 . 8 5 8}$, $p$-value $\left.=0.0001\right)$ were significantly associated with $C C A$ risk. Spatial distribution of the population at risk for CCA in Chum Phuang district was viewed with Google Earth. Geo-visual display followed Layer 1: District, Layer 2: Sub-district, Layer 3: Number of low risk in village, Layer 4: Number of high risk in village, and Layer 5: Hospital in Chum Phuang District and their related catchment areas. Conclusions: We present the first risk geo-visual display of CCA in this rural community, which is important for spatial targeting of control efforts. Risk appears to be strongly associated with gender, age group, and sub-district. Therefor, spatial distribution is suitable for the use in the further monitoring, surveillance, and home health care for CCA.
\end{abstract}

Keywords: Spatial distribution - population at risk - cholangiocarcinoma - Nakhon Ratchasima - Thailand

Asian Pac J Cancer Prev, 17 (2), 719-722

\section{Introduction}

Cholangiocarcinoma (CCA) is known to be one of the most common causes of cancer related to death in Thailand where is the highest incident of the world (Green et al., 1991; Sripa et al., 2007; Shin et al., 2010). CCA is a neoplasm that involves the epithelial cells of the bile duct. This disease is difficult to have early diagnosis, as most symptoms present late in the disease course. In addition, CCA is considered to be an incurable and rapidly lethal disease unless all the tumors can be fully resected. Three-year survival rates of $35 \%$ to $50 \%$ are achieved only in a subset of patients who have negative histological margins at the time of surgery (Akamatsu et al., 2011). To e encourage patients to see health personnel at early stage is very important (Thunyaharn et al., 2013).

The high mortality rate of CCA was reported in the northeast areas where found frequently of Opisthorchis viverrini infection (Sripa et al., 2011). Recently, $O$. viverrini has been classified as Type 1 carcinogens by

${ }^{1}$ Parasitic Disease Research Unit, ${ }^{2}$ School of Family Medicine and Community Medicine, ${ }^{3}$ Suranaree University of Technology Hospital, Suranaree University of Technology, ${ }^{5}$ Social Development Program, Faculty of Humanities and Social Science, ${ }^{6}$ Environmental Technology Program, ${ }^{7}$ Faculty of Public Health, Nakhon Ratchasima Rajabhat University, ${ }^{8}$ Faculty of Public Health, Vongchavalitkul University, Nakhon Ratchasima, ${ }^{4}$ Geographic Information Technology Program, Faculty of Information Technology, Rajabhat Maha Sarakham University, Maha Sarakham, Thailand*For correspondence: soraya.k@sut.ac.th 
the International Agency for Research on Cancer, World Health Organization (WHO) (IARC, 1994). Mortality rate of liver cancer and $O$. viverrini infection rate in different regions of Thailand has been reported and found that Nakhon Ratchasima province has 13.67-16.2 per 100,000 populations (Sripa et al., 2008). In addition, the distribution $O$. viverrini infection in Nakahon Ratchasima province has been reported, the prevalence of survey in 2009 was $4.6 \%$ (Sitthithaworn et al., 2012). A total of 1,168 stool samples were obtained from 516 males and 652 females. Stool examination showed that $2.48 \%$ were infected with O. viverrini (Kaewpitoon et al., 2012c).

Recently, we have been utilized the GIS and Google Earth $^{\mathrm{TM}}$ for distribution mapping of CCA in Satuek district, Buriram, Thailand, during a 5-year period (2008-2012), and found that the GE production process is very simple and easy to learn. It is suitable for the user in the further CCA management strategy (Rattanasing et al., 2015). Rujirakul et al. (2015) have been investigated the human behavior, and environmental factors influencing the distribution in Surin Province of Thailand. The combination of GIS and statistical analysis can help simulate the spatial distribution and risk areas of liver fluke, and thus may be an important tool for future planning of prevention and control measures. Therefore, the spatial distribution of the population at risk for CCA is conducted in Chum Phuang district, Nakhon Ratchasima province, Thailand, using geographic information system and Google Earth. This data is useful for further monitoring, surveillance, and home visit the population at risk.

\section{Materials and Methods}

\section{Study location and population}

The study was conducted in Chum Phuang district, Nakhon Ratchasima province, northeast Thailand, between June and October 2015. The study protocol was approved by Suranaree University Ethical Review Committee, EC58-48. Chum Phuang is a district in the eastern part of Nakhon Ratchasima province, located in coordinates: $15^{\circ} 20{ }^{\prime} 56^{\prime \prime} \mathrm{N} 102^{\circ} 44^{\prime} 31$ 'E. Neighboring districts are (from the north clockwise) Prathai, Mueang Yang and Lam Thamenchai of Nakhon Ratchasima Province, Lam Plai Mat of Buriram Province, and Huai Thalaeng and Phimai of Nakhon Ratchasima again. The district is subdivided into 9 sub-districts. Chum Phuang is the only township of the district, covering parts of the Chum Phuang sub-district. There are further 9 sub-district administrative organizations, including Chum Phuang, Prasuk, Tha Lat, Sarai, Talat Sai, Non Rang, Non Lak, Non Tum, and Non Yo. Chum Phuang district is coverage areas 540.6 Kilometer2 (208.7 sq mi), and has 83,096 populations. A total of 11,960 populations who have age over 35 years old, was purposive selected and completed the verbal screening.

Populations at risk for CCA, were screened by using Korat CCA verbal screening test (KCVST) which contained the history with (1) opisthorchiasis (2) undercooked fish consumption, (3) praziquantel used (4) cholangitis or cholecystitis, (5) relative family with CCA (6) naïve northeastern people, (7) agriculture, and (8) alcohol consumption. Scores were summarized following $1+2+3+4+5+6+7+8$, and calculated the population at risk; none ( 0 point), low (1-4 point), and high risk (5-8 point) (Table 1).

\section{Software, data collection and management}

Software were used in this study, including Microsoft excel, ArcGIS 10.2, and Google Earth. Spatial database was contained the point of villages, sub-district boundaries, district boundaries, and point of hospital in Chum Phuang district. Attribute database was contained the populations at risk for CCA; low and high risk, opisthorchiasis, and CCA. Data management were collected the spatial database and then tranfered to WGS84 UTM ZONE 48. Village point, where had the populations at risk for CCA, opisthorchiasis, abnormal bile duct, and CCA, were used to analyze and calculate with ArcGIS 10.2. After the conversion, all of the data were imported into Google Earth (GE) using online web pages www.earthpoint.us. This web pages using HTML codes (village point was a primary key) to export the coordinate to $\mathrm{kml}$ format that can be recognized by GE (Figure 1). Geovisual display of the population at risk for CCA on the Google Maps in this study include 5 layers, for each layer using could be click scroll and choos $\square$ (Figure 2); layer 1; district, layer 2; sub-district, layer 3; low risk, layer 4; high risk, layer 5; hospital in Chum Phuang District.

\section{Results}

A total of 11,960 population from 83,096 population, were included in this study, indentified to gender; male $(47.81 \%)$, female $(52.52 \%)$. The majorities of population were age group $41-50$ years old $(33.32 \%)$, followed by 51-60 years old (33.04\%), and 61-70 years old (16.68\%). The most of them was habited in Ta Lat $(17.78 \%)$, and followed by Prasuk (14.93\%), and Tala Sai (12.80\%). Population at risk was identifed to low risk (92.77\%), and followed by high risk $(6.74 \%)$, and none of risk $(0.49 \%)$, respectively. Gender $\left(\mathrm{X}^{2}\right.$-test $=1143.63$, $\mathrm{p}$-value $=$ 0001), age group $\left(\mathrm{X}^{2}\right.$-test $==211.36$, $\mathrm{p}$-value $\left.=0.0001\right)$, and sub-district $\left(\mathrm{X}^{2}\right.$-test $=1471.858, \mathrm{p}$-value $\left.=0.0001\right)$ were

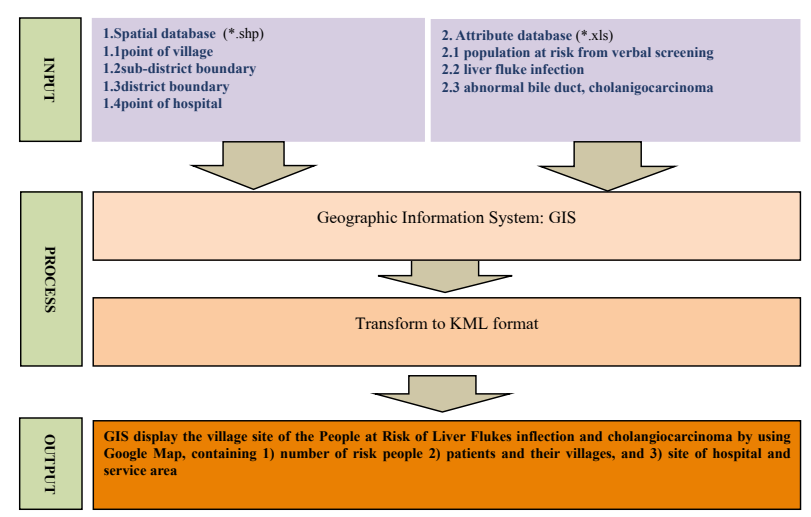

Figure 1. Diagrammatic of Utilized Geographic Information System and Google Map for Monitoring and Surveillance the Population at Risk of Cholangiocarcinoma in Chum Phuang District, Nakhon Ratchasima Province, Thailand 
Spatial Distribution of Populations at Risk of Cholangiocarcinoma in Nakhon Ratchasima Province of Thailand statistical significant associated to CCA risk (Table 1).

Spatial distribution of the population at risk for CCA in Chum Phuang district has been viewed in Google

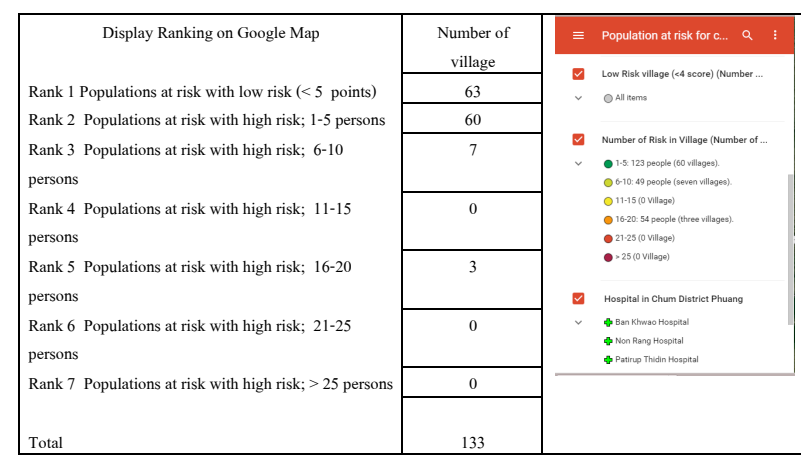

Figure 2. Ranking and Attribute Data of Population at Risk for Cholangiocarcinoma in Chum Puang District, Nakhon Ratchasima Province, Thailand

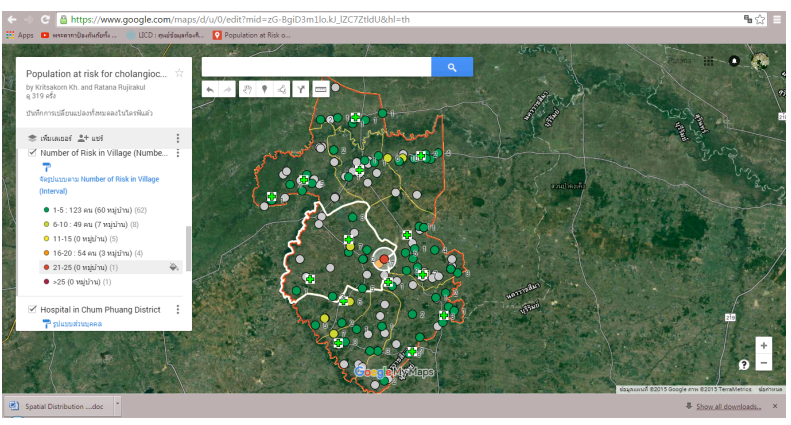

Figure 3. Geo-visual Display of Population at Risk for Cholangiocarcinoma in Chum Phuang District, Nakhon Ratchasima Province, Thailand, Using Google Map
Earth following https://www.google.com/maps/d/ viewer?hl=th\&authuser $=0 \& \mathrm{mid}=\mathrm{zG}-\mathrm{BgiD} 3 \mathrm{~m} 1 \mathrm{lo} . \mathrm{kJ}$ 1ZC7ZtldU (Figure 3,4). Geo-visual display was followed;

Layer 1 Chum Phuang district (Number of Sub District); Attributed data was displayed the district border with 9 sub-districts and 133 villages. Google map was displayed village location and the symbol of number of the population at risk in each village.

Layer 2 Sub-district (Number of Village); Attributed data was displayed the sub-district border with 9 subdistricts. Google map was displayed village location and the symbol of number of the population at risk in each village within sub-order of sub-district.

Layer 3 Number of low risk in village (Number of Village); Attributed data was displayed the village location. Google map was displayed village location and the symbol of number of the population at low risk in each village, 63 villages, within the sub-order of sub-district.

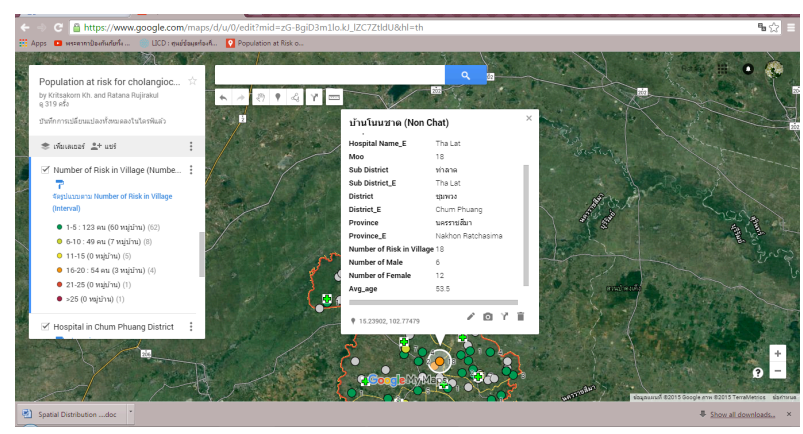

Figure 4. Geo-visual Display of Population at Risk for Cholangiocarcinoma of Village in Chum Phuang District, Nakhon Ratchasima Province, Thailand, by Using Google Map

Table 1. Population at Risk for Cholangiocarcinoma in Chum Phuang District, Nakhon Ratchasima Province, Thailand, Using Korat CCA Verbal Screening Test

\begin{tabular}{|c|c|c|c|c|c|c|c|c|}
\hline \multirow[t]{3}{*}{ Characteristics } & \multicolumn{6}{|c|}{ Risk for CCA } & \multirow{2}{*}{\multicolumn{2}{|c|}{ Total }} \\
\hline & \multicolumn{2}{|c|}{ None } & \multicolumn{2}{|c|}{ Low } & \multicolumn{2}{|c|}{ High } & & \\
\hline & $\mathrm{n}$ & $\%$ & $\mathrm{n}$ & $\%$ & $\mathrm{n}$ & $\%$ & $\mathrm{n}$ & $\%$ \\
\hline Gender & 59 & 0.49 & 11,131 & 92.77 & 809 & 6.74 & 11,999 & 100.00 \\
\hline Male & 29 & 0.24 & 5,191 & 43.26 & 498 & 4.15 & 5,718 & 47.81 \\
\hline Female & 30 & 0.25 & 5,940 & 49.50 & 311 & 2.59 & 6,281 & 52.52 \\
\hline \multicolumn{9}{|c|}{ Pearson Chi-Square $=1143.63, \mathrm{p}-$ value $=0001$} \\
\hline Age group & 46 & 0.38 & 11,155 & 92.97 & 798 & 6.65 & 11,999 & 100.00 \\
\hline$<40$ & 4 & 0.03 & 1,235 & 10.29 & 65 & 0.54 & 1,304 & 10.87 \\
\hline $41-50$ & 10 & 0.08 & 3,719 & 30.99 & 269 & 2.24 & 3,998 & 33.32 \\
\hline $51-60$ & 13 & 0.11 & 3,636 & 30.30 & 315 & 2.63 & 3,964 & 33.04 \\
\hline $61-70$ & 12 & 0.10 & 1,865 & 15.54 & 125 & 1.04 & 2,002 & 16.68 \\
\hline$>70$ & 7 & 0.06 & 700 & 5.83 & 24 & 0.20 & 731 & 6.09 \\
\hline \multicolumn{9}{|c|}{ Pearson Chi-Square $=211.36, \mathrm{p}$-value $=0.0001$} \\
\hline Sub-district & 46 & 0.38 & 11,155 & 92.97 & 798 & 6.65 & 11,999 & 100.00 \\
\hline Chum Phuang & 18 & 0.15 & 1,242 & 10.35 & 42 & 0.35 & 1,302 & 10.85 \\
\hline Tala Sai & 0 & 0.00 & 1,454 & 12.12 & 82 & 0.68 & 1,536 & 12.80 \\
\hline Ta Lat & 9 & 0.08 & 1,924 & 16.03 & 201 & 1.68 & 2,134 & 17.78 \\
\hline Prasuk & 5 & 0.04 & 1,728 & 14.40 & 59 & 0.49 & 1,792 & 14.93 \\
\hline Salai & 3 & 0.03 & 525 & 4.38 & 114 & 0.95 & 642 & 5.35 \\
\hline Nong Luk & 0 & 0.00 & 719 & 5.99 & 42 & 0.35 & 761 & 6.34 \\
\hline Non Tum & 7 & 0.06 & 1,357 & 11.31 & 83 & 0.69 & 1,447 & 12.06 \\
\hline Non Yo & 3 & 0.03 & 915 & 7.63 & 81 & 0.68 & 999 & 8.33 \\
\hline Non Rang & 1 & 0.01 & 1,290 & 10.75 & 94 & 0.78 & 1,385 & 11.54 \\
\hline \multicolumn{9}{|c|}{ Fisher's Exact Test $=1471.858, \mathrm{p}$-value $=0.0001$} \\
\hline
\end{tabular}


Layer 4 Number of high risk in village (Number of Village); Attributed data was displayed the villages with the each ranking risk, 226 persons and 70 villages. Google map was displayed village location and the symbol of number of the population at risk in each village within sub-order of sub-district.

Layer 5 Hospital in Chum Phuang District; Attributed data was displayed the hospital in this district. Google map was displayed hospital location and the related catchment areas.

\section{Discussion}

CCA is still a serious public health problem in Nakhon Ratchasima province of Thailand. Mortality rate of liver cancer has been reported and found that Nakhon Ratchasima province has 13.67-16.2 per 100,000 populations (Sripa et al., 2011). Worldwide, it has an annual incidence rate of 1-2 cases per 100,000 (Landis et al., 1998; Patel, 2002). Here we active surveillance by using verbal screening test and found that a total of 809 $(6.74 \%)$ the population at risk for CCA, was a high risk group. The majorities of population were age group 41-50 years old, followed by 51-60 years old, and 61-70 years old. The most of them was habited in Ta Lat, and followed by Prasuk, and Tala Sai. In addition, we found that gender, age group, and sub-district were statistical significant associated to CCA risk. Previously study reported that $O$. viverrini, the one caused of CCA, found frequently in this district particularly in the elderly age and male (Kaewpitoon et al., 2012c).This figure indicates that CCA is still a major problem in Chum Phuang district, Nakhon Ratchasima province particularly in the rural communities.

The utilized the GIS and Google Earth ${ }^{\mathrm{TM}}$ for distribution mapping of CCA has been reported in Satuek district, Buriram, Thailand, and found that the GE production process is very simple and easy to learn. It is suitable for the user in the further CCA management strategy (Rattanasing et al., 2015). Furthermore, the combination of GIS and statistical analysis can help simulate the spatial distribution and risk areas of liver fluke in Surin proivince, Thailand. Here we have shown the spatial distribution of the population at risk for CCA in Chum Phuang district. The 5 layers have been applied for geo-visual display of CCA, briefly, layer 1: Chum Phuang District; displayed the district border with 9 sub-districts and 133 villages. Layer 2: Sub District; displayed the sub-district border with 9 sub-districts. Layer 3 Number of low risk in village; displayed the village location and the population at low risk in each village, 63 villages, within the sub-order of sub-district. Layer 4: Number of high risk in village; displayed the villages with the each ranking risk, 226 persons and 70 villages. Layer 5: Hospital in Chum Phuang District; displayed the hospital in this district, and the related catchment areas. This geovisual display is used for further monitoring, surveilance, and long-term health care.

We present the first risk geo-visual display of CCA in Chum Phuang district, Nakhon Ratchasima province, which is important for spatial targeting of control efforts. Population at risk appears to be strongly associated with gender and age group in this district. Therefor, spatial distribution is suitable for the use in the further monitoring, surveillance, and home health care for CCA.

\section{Acknowledgements}

This monitoring and surveillance tool development was supported by National Health Security Office of Nakhon Ratchasima province, through health promotion and prevention fund, year 2015. Special thanks all staffs of district public health organization of Chum Phuang for their assistance.

\section{References}

Akamatsu N, Sugawara Y, Hashimoto D (2011). Surgical strategy for bile duct cancer: Advances and current limitations. World J Clin Oncol, 10, 94-107.

Green A, Uttaravichien T, Bhudhisawasdi V, et al (1991). Cholangiocarcinoma in northeast Thailand. A hospital-based study. Trop Geogr Med, 43, 193-8.

IARC. (1994). Infection with liver flukes (Opisthorchis viverrini, opisthorchis felineus and clonrochis sinensis). IARC Monogr Eval Carcinog Risks of Hum, 61, 121-75.

Kaewpitoon SJ, Rujirakul R, Kaewpitoon N (2012). Prevalence of Opisthorchis viverrini infection in Nakhon Ratchasima province, Northeast Thailand. Asian Pac J Cancer Prev, 13, 5245-9.

Landis S, Murray T, Bolden S, et al (1998). Cancer statistics, 1998. CA Cancer J Clin, 48, 6-29.

Patel T (2002). Worldwide trends in mortality from biliary tract malignancies. BMC Cancer, 2, 10.

Poomphakwaen K, Promthet S, Kamsa-ard S, et al (2009). Risk factors for cholangiocarcinoma in KhonKaen, Thailand: A nested case-control study. Asian Pac J Cancer Prev, 10, $251-7$.

Rattanasing W, Kaewpitoon SJ, Loyd RA, et al (2015). Utilization of google earth for distribution mapping of cholangiocarcinoma: a case study in satuek district, buriram, Thailand. Asian Pac J Cancer Prev, 16, 5903-6.

Rujirakul R, Ueng-arporn N, Kaewpitoon S, et al (2015). GISbased spatial statistical analysis of risk areas for liver flukes in Surin Province of Thailand. Asian Pac J Cancer Prev, 16, 2323-6.

Shin HR, Oh JK, Masuyer E, et al (2010). Epidemiology of cholangiocarcinoma: an update focusing on risk factors. Cancer Sci, 101, 579-85.

Sripa B, Kaewkes S, Sithithaworn P M, et al (2007). Liver fluke induces cholangiocarcinoma. PLoS Med, 4, 201.

Sripa B, Pairojkul C (2008). Cholangiocarcinoma: lessons from Thailand. Curr Opin Gastroenterol, 24, 349-56.

Sripa B, Bethony JM, Sithithaworn P, et al (2011). Opisthorchiasis and opisthorchis-associated cholangiocarcinoma in Thailand and Laos. Acta Trop, 120, 158-68.

Thunyaharn N, Promthet S, Wiangnon S, et al (2013). Survival of cholangiocarcinoma patients in northeastern Thailand after supportive treatment. Asian Pac J Cancer Prev, 14, 7029-32. 